\section{A Medicina Rastafári e as possíveis relações com a Naturologia}

\section{The Rastafári Medicine and possible relation with the Naturology}

\section{RESUMO}

O presente estudo tem como objetivo identificar a concepção de saúde e as práticas terapêuticas utilizadas pela medicina Rastafári e estabelecer uma possível relação com a Naturologia. Estudo de caráter descritivo e analítico de abordagem qualitativa, foi elaborado por meio de pesquisas em bases de dados científicos online e físicos e por levantamento de campo em que foram entrevistadas onze pessoas, sendo elas sacerdotes, profetas e praticantes da Cultura Rastafári no Brasil. A pesquisa possibilitou encontrar informações importantes sobre a Cultura Rastafári, sendo possível elucidar que, assim como a Naturologia, a cosmologia dessa cultura possui caráter multidimensional e complexo, traços esses característicos do paradigma vitalista em saúde e propõe que o olhar terapêutico seja integrativo. A análise dos dados de pesquisa sugere que a Medicina Rastafári pode ser entendida como uma linha terapêutica compatível com as práticas da Naturologia, por apresentar conceitos semelhantes e afinidades ao pensamento Naturológico, como a visão integrativa da saúde e o uso de recursos terapêuticos naturais.

\section{PALAVRAS-CHAVE}

Medicina Rastafari.

Medicina Tradicional.

Bush Doctors.

Naturologia.

Saúde Natural.
Igor Azevedo Silva

- Bacharel em Naturologia pela UAM. 2014.

Carolina Ruiz

- Gestora Ambiental. Bacharelanda em Naturologia pela UAM. 2018.

Caio Fábio Schlechta Portella

- Naturólogo com formação especifica em Fitoterapia pela Universidade Anhembi Morumbi, Mestre em ciências pela Faculdade de Saúde Publica da Universidade de São Paulo, Coordenador e Docente do curso de Naturologia da Universidade Anhembi Morumbi, Editor Associado da Revista Cadernos de Naturologia e Terapias Complementares - CNTC, Sócio Fundador e Diretor de Tecnologias da Informação da Sociedade Brasileira de Naturologia - SBNAT, Sócio fundador da APANAT - Associacão Paulista de Naturologia, Docente da PósGraduação em Dor e Pós-Graduação em Ortopedia Multiprofissional do Instituto Israelita Albert Einstein, Naturólogo no Instituto

Transdisciplinar Intedor e Espaço Integral Saúde

Adriana Elias Magno da Silva

- Professora da Universidade Anhembi Morumbi. Doutora Em Antropologia pela PUC/SP.DOI: 10.19177/cntc. v6e11201721-32

DOI: $10.19177 /$ cntc.v7e12201823-32

\section{CORRESPONDENTE}

R. Casa do Ator, 275 - Vila Olimpia São Paulo - SP, 04546-001

E - M A I L

igordeazevedo@hotmail.com

Recebido: 18/10/2017

Aprovado: 13/09/2018 


\begin{abstract}
The present study aims to identify the health conception and the therapy practice used by the Rastafari Culture and establish a possible relation with the Naturology. A descriptive and analytical study of a qualitative approach was elaborated through researches in online and physical scientific databases and field survey where eleven people were interviewed, being they priests, prophets and practitioners of the Rastafari Culture in Brazil. The research made it possible to find important information about Rastafari Culture, and it is possible to elucidate that, like Naturology, the cosmology of this culture has a multidimensional and complex character, traits that are characteristic of the vitalist paradigm in health and proposes that the therapeutic look be integrative. The analysis of the research data suggests that Rastafari Medicine can be understood as a therapeutic line compatible with the practices of Naturology, because it presents similar concepts and affinities to Naturological thinking, such as the integrative vision of health and the use of natural therapeutic resources.
\end{abstract}

KEY WORDS: Traditional Medicine. Bush Doctors. Natural Health. Naturology

\section{INTRODUÇÃO}

Buscando o resgate e a valorização das medicinas tradicionais e métodos naturais de prevenção de doenças, manutenção e recuperação de saúde, integrando-os aos princípios científicos da medicina ocidental, a Naturologia destaca-se por utilizar do conhecimento de filosofias ancestrais tradicionais como ferramenta de trabalho terapêutico e clínico. Atualmente é possível encontrar estudos acadêmicos científicos sobre essas medicinas e terapêuticas, o que contribui para a ampliação da visão e abordagem da área da saúde.

A Naturologia é um conhecimento caracterizado pela mescla de racionalidades médicas, de filosofias e de técnicas de cura orientais, ocidentais, modernas e tradicionais. É um fenômeno decorrente da crise de paradigmas do mundo contemporâneo e da necessidade de revisão e ampliação dos modelos de práticas médicas vigentes. Apresenta-se como um conhecimento transdisciplinar filiado a modelos integrativos e complementares de atuação e atenção em saúde. (Silva $\left.{ }^{1}\right)$

No contexto desta ampliação da abordagem em saúde, estudar outras medicinas e Racionalidades Médicas pode contribuir para a transformação do modelo de práticas médicas vigente. Tendo em vista que a Cultura Rastafári utiliza de terapias já analisadas em outros contextos no meio cientifico-acadêmico e na Naturologia como: Meditação, Alimentação Natural, Musicoterapia, Fitoterapia; entre outras. O Objetivo deste artigo é mapear, a partir de representantes brasileiros da Cultura Rastafári, a concepção de saúde, as práticas terapêuticas e estabelecer uma possível relação com a Naturologia. Este estudo é inédito na literatura, pois não foram encontrados outros trabalhos acadêmicos que abordassem o tema.

\subsection{RAS TAFARI: O NASCIMENTO DE UMA CULTURA}

A Cultura Rastafári é baseada e norteada pelo amor, orgulho e respeito à herança ancestral africana. Possui principal local de preservação na Jamaica, uma ilha do mar do caribe que se encontra na América central. A Cultura Jamaicana, atualmente, é o resultado da interação de diversas culturas. Durante o século XVI, a população nativa foi dizimada pelos colonizadores europeus e pelas doenças trazidas por eles. No século seguinte, os ingleses conquistaram a Jamaica e a controlaram até sua independência em 1962. Os escravos trazidos da África para trabalhar nas plantações formam a maioria da população ${ }^{2}$.

A emancipação dos escravos em 1838 não eliminou os efeitos da escravidão na sociedade jamaicana. Desde os tempos de escravidão que os afrodescendentes se rebelam contra a exploração e a marginalização que sofrem. Inicialmente, essa resistência 
se fazia pelos marrons (espécie de quilombos) muitas vezes chefiados por xãmas (obeah-myal), os quais eram temidos pela população branca. Em meio a esta atmosfera, começaram a circular as ideias do pregador jamaicano e profeta Marcus Garvey, que deu origem ao Garveyismo; por volta de 1912 declarou: "Voltem os olhos para a África, para a coroação de um rei negro. Ele será o redentor". Em 1930, a profecia se cumpriu com a coroação do Imperador Haile Selassie I da Etiópia (nome que recebeu ao tornar-se imperador, que significa o poder da santíssima trindade), o Leão conquistador de Judá, a raiz de Davi (Selassie é descendente direto do rei Davi citado na bíblia). Na Etiópia seu título era Negus Ras Tafari, pois seu nome de batismo é Tafari Makonen ${ }^{3}$.

O movimento Rastafari surgiu aproximadamente em 1933 como um movimento religioso e de contestação econômica, politica e social contra a opressão britânica e a marginalização da população afro-jamaicana. O Rastafári considera que o Imperador Haile Selassie I veio para cumprir as profecias bíblicas de destruição da babilônia e de redenção dos fiéis, que ele é a reencarnação de Jesus Cristo ou Deus Pai em carne. Além de ser formado por diversas fontes de estudo como a Cultura Ancestral, a Bíblia, o Etiopianismo, o Pan-Africanismo, o Garveyismo entre muitas outras. As discussões acadêmicas sobre o Rastafári discordam quanto a sua definição e quanto à própria natureza do movimento. $O$ Rastafári possui múltiplas facetas, podendo ser reconhecido e definido de maneiras diferentes por se tratar de um conhecimento complexo e amplo em vários aspectos ${ }^{4}$.

Além de possuir o caráter político, religioso e cultural o Rastafári se destaca por ser altamente musical, um de seus principais costumes é o louvor em forma de Nyahbinghi, oração e cantos ritmados pelo toque do coração em tambores africanos ${ }^{5}$. Também conhecidos mundialmente pela música reggae, que em sua essência dissemina letras que apresentam uma visão crítica, contestadora, educativa, espiritual e de resgate da cultura negra; com traços musicais que vão desde música de igreja, música caribenha, música americana até a música folclórica e outros ritmos ${ }^{6}$.
$\mathrm{Na}$ raiz desta cultura, os adeptos a este estilo de vida possuem total integração com a natureza, utilizam de ervas e plantas medicinais, bem como meditação e alimentação natural como meio de purificação e manutenção de saúde, muitos dos seus costumes são também justificados por versículos e estudos da Bíblia ${ }^{7}$.

Em meio a esta realidade encontramos alguns Rastafáris conhecidos como Bush Doctors ou em português, doutores do mato, que trabalham com tratamentos medicinais, produzindo e vendendo chás e remédios à base de plantas medicinais. Por buscarem uma vida natural, a grande maioria rejeita a utilização de substâncias químicas artificiais no cuidado com a saúde, o que mantém um grande nicho de remédios à base de plantas e receitas tradicionais. Os Bush Doctors são reconhecidos pelos jardins de plantas medicinais e pela transmissão do conhecimento etnomedicinal, desta forma retificam sua ideologia reposicionando o negro e o mestiço em uma posição menos marginalizada e mais atuante na sociedade, além de trazer a unificação de conhecimentos e remédios africanos ${ }^{8}$.

Existem também médicos Rastafáris que trabalham com várias técnicas terapêuticas como: alimentação natural, utilização de chás e compostos fitoterápicos, massoterapia, entre outras. Hon Priest Kailash Kay Leone é uma boa referência para explicar a atuação destes profissionais. Seu aprendizado inclui técnicas medicinais tradicionais aprendidas com a avó mescladas ao seu curso de medicina ocidental ${ }^{9}$. Fundou um centro de saúde que conta com Restaurante, Clínica Médica e Farmácia Viva, tudo no mesmo lugar, oferecendo manutenção e recuperação da saúde através de alimentos, consultas, produtos, aulas de culinária e de formação. Iniciou um processo de educação em saúde através de programas de rádio, televisão e publicou três livros na área da saúde.

No Brasil inicialmente em 1970 o reggae e o Rastafári eram encontrados apenas em São Luís do Maranhão, porém posteriormente se espalhou por todo país. A Cultura Rastafári foi recebida e adaptada a nossa realidade e costumes com a disseminação da 
música reggae pelo Brasil. Muitos começaram a se interessar, com o passar do tempo tornaram-se adeptos, e hoje divulgam essa ideologia através de inúmeras formas, que vão da música, arte, até a política ou culto religioso, afinal, nosso país, assim como a Jamaica, é rico em afrodescendentes ${ }^{10}$.

\section{METODOLOGIA}

Este artigo é fruto de um estudo descritivo e analítico de abordagem qualitativa, realizado entre abril e novembro de 2014, aprovado pelo Comitê de Ética em Pesquisa da Universidade Anhembi Morumbi UAM, sob o número CAAE 32042014.4.0000.5492 da Plataforma Brasil.

A pesquisa bibliográfica foi realizada a partir de bases de dados científicas online e físicas e literatura específica sobre o assunto, foi realizada a busca do tema nos respectivos bancos de dados: Pubmed, Scielo, Lilacs, Scopus, Scholar Google e biblioteca Anhembi Morumbi. O levantamento das fontes bibliográficas foi estruturado a partir das seguintes palavras chaves: história do Rastáfari, costumes Rastafáris, saúde Rastáfari, Rastáfari e a bíblia, praticas médicas do Rastafári, alimentação Rastafári, meditação Rastafári, Bush Doctors e musica Rastáfari.

O levantamento de campo foi realizado através de entrevistas estruturadas, formadas por dez questões abertas que inquiriam sobre: o que é Rastafari, sua relação com natureza, o que é saúde, como é sua alimentação, o que é meditação, como utilizam as plantas medicinais, qual o papel da música, como contribuem para educação em saúde e como contribuem para a saúde integral, todos os participantes responderam as mesmas perguntas, uma única vez, seguindo a abordagem de campo convencional nas ciências sociais de entrevista direta com os informantes. Segundo Chizzotti1" "Na pesquisa qualitativa, todas as pessoas que participam da pesquisa são reconhecidas como sujeitos que elaboram conhecimentos e produzem práticas adequadas para intervir nos problemas." A coleta de dados foi realizada no estado de São Paulo, de forma presencial ou on-line dependendo da proximidade geográfica e disponibilidade de tempo dos informantes, os quais foram iden- tificados com base numa estratégia conhecida como bola-de-neve, onde cada participante indicava outras pessoas para participarem da pesquisa ${ }^{12}$.

Estabeleceu-se como critério de inclusão ou exclusão, selecionar apenas praticantes da Cultura Rastafári (em suas diversas linhas de estudo) como participantes da pesquisa. Sua disponibilidade de tempo e abertura para a participação do projeto também foram considerados.

\subsection{CARACTERÍSTICA DA AMOSTRA}

Foram contatados vinte praticantes do Rastafari no Brasil, dos quais, onze aceitaram participar da entrevista (oito do sexo masculino e três do sexo feminino). Dentre eles cinco da ordem Boboshanti, três da ordem Nyahbinghi e nenhum da linhagem Doze tribos (não foram encontrados praticantes desta linha nesta pesquisa), dois sem linha de estudo definida e um que afirmou ser de todas as linhas.

Cabe ressaltar que não foi encontrado nenhum médico Rastafári, Bush doctor ou praticante que foque seus estudos e práticas no conhecimento medicinal do Rastafári para a participação na entrevista, portanto o conceito de Medicina Rastafári proposto nesta pesquisa é baseado nos relatos de Sacerdotes, Profetas e praticantes em geral, o que revela como são raros, no Brasil, os praticantes que focam seus trabalhos e estudos no quesito medicinal do Rastafári.

Nas falas extraídas das entrevistas, foram utilizadas siglas referentes às iniciais de letra de cada linha de estudo do Rastafári, sendo, BS (Boboshanti); NB (Nyahbinghi); SLD (Sem linha definida) e OL (Outras Linhas), seguida do número atribuído a cada indivíduo participante por ordem crescente baseada na data de coleta das respostas dentro da linha de estudo que pertence.

\section{DISCUSSÃO DAS CATEGORIAS E DIMENSÕES COMO SIGNO DE COMENSURABILIDADE}

$\mathrm{O}$ processo de análise dos dados deste estudo possibilitou encontrar informações e reflexões sobre a visão de mundo, conceito de saúde e doença, cos- 
tumes de obtenção e manutenção de saúde, técnicas medicinais para prevenção e tratamento de doenças.

A organização dos discursos em categorias temáticas foi inspirada no conceito de racionalidade médica de Madel Luz ${ }^{13}$.

As informações obtidas através da pesquisa bibliográfica e do levantamento de campo não foram suficientes para enquadrar o conhecimento Rastafári nas dimensões que caracterizam uma racionalidade médica segundo Luz ${ }^{13}$. Optou-se por utilizar como recurso de organização da pesquisa a utilização de três das seis dimensões que compõe a categoria Racionalidade Médica definidas por Luz ${ }^{13}$. Foram elas: Cosmologia, Doutrina Médica e Sistema Terapêutico.

\subsection{COSMOLOGIA}

Racionalidade médica, segundo Luz ${ }^{13}$, é uma categoria conceitual metodológica inspirada na noção de tipo ideal weberiano. Segundo Tesser e Luz ${ }^{14}$

Uma racionalidade médica é um conjunto integrado e estruturado de práticas e saberes composto de cinco dimensões interligadas: uma morfologia humana (anatomia, na biomedicina), uma dinâmica vital (fisiologia), um sistema de diagnose, um sistema terapêutico e uma doutrina médica (explicativa do que é a doença ou adoecimento, sua origem ou causa, sua evolução ou cura), todos embasados em uma sexta dimensão implícita ou explícita: uma cosmologia. Através dessa delimitação, precisa e específica, pode-se distinguir entre sistemas médicos complexos como a biomedicina ou a medicina tradicional chinesa e terapias ou métodos diagnósticos isolados ou fragmentados, como os florais de Bach ou a iridologia, que hoje proliferam na cultura alternativa do pós anos 60 e da nova era.

Para Nascimento et $\mathrm{al}^{15}$ a Cosmologia tem a função de embasar teórica e simbolicamente as cinco dimensões, seu caráter elaborado e sistemático qualifica as raízes filosóficas das racionalidades médicas. A visão cosmológica da biomedicina, por exemplo, está sustentada na física clássica newtoniana e na metáfora cartesiana do corpo como máquina direcionada pela mente, enquanto na Medicina Ayurveda e na Medicina Tradicional Chinesa, a cosmologia está enraizada em conhecimentos filosóficos, religiosos e espirituais, como a cultura védica, da Índia e o taoísmo chinês. Segundo o relato dos entrevistados a definição de cosmologia da medicina Rastafári está diretamente ligada à história e as culturas da África, e da incorporação dos princípios do Etiopianismo pelo povo jamaicano. Nota-se nas falas uma ligação com concepções que mesclam princípios naturalistas e religiosos num livre trânsito entre valores de culturas ancestrais e princípios hebreus como o monoteísmo. Por ser baseado e estruturado a partir do resgate das culturas africanas, o Rastafári recupera o estilo de vida das primeiras civilizações humanas, tendo em vista que a África é o berço da humanidade e que todos os seres humanos possuem esta mesma origem, as visões de mundo de origem africana podem ser consideradas as visões de mundo dos mais antigos ancestrais humanos.

[...] África é o berço de todas as civilizações, então todas as relações com os elementos, tanto as plantas, como o fogo, a terra, a água e o ar primeiramente foi iniciado na África [...] (BS1).

[...] Rastafári é um modo de vida com raízes na Etiópia. É a maneira original de se viver, a verdadeira essência humana. É o resgate da nossa consciência ancestral e espiritualidade que foi sendo perdida com o tempo [...] (BS3).

Sustentabilidade e a ecologia são traços marcantes do Rastafári, os praticantes buscam viver em comunhão com a natureza e gerar o mínimo de impacto ambiental possível.

[...] se prefere a utilização de materiais biodegradáveis para a construção de moradias, confecção de roupas e todo o mais. Busca-se uma vida sustentável em todos os aspectos, reciclando os dejetos secos e orgânicos, restringido ao mínimo ou zero o lixo dispensado (BS3).

[...] para nós mulheres Rastafaris é de extrema importância ter essa conexão com a terra, pois através dela renovamos e geramos vida. Voltando nosso ciclo menstrual ao natural, purificação, então devolvemos nosso sangue a terra, ensinamento de nossas ancestrais, obtendo a reconexão com a mãe natureza e evitando degradar o meio ambiente (BS3).

Os relatos acima ajudam a constituir a Cosmologia que embasa a visão Rastafári em que o ser humano não se encontra separado da natureza e sim em total harmonia e integração com o ambiente. A natureza não é vista como um objeto à disposição do ser humano, ao contrário, é resgatada a visão sistêmica que entende a natureza como um todo integrado e interdependente, em que o ser humano faz parte e deve preservar a natureza, noção 
esta, indispensável para a preservação da vida na Terra $^{16}$. Assim como sugere Capra e Eichemberg ${ }^{17}$, as concepções naturalistas apresentam uma ligação mais orgânica entre o ser humano e a natureza. O homem tem a sensação de pertencimento, de conexão com o cosmos.

Nesta consciência de integralidade, conexão e pertencimento, o Rastafári reconhece que o Criador, Deus, vive em tudo e em todos nós, Deus é a fundamentação dessa visão conectada. A concepção Rastafári sobre a noção de Deus pode ser entendida como uma visão interacional entre parte e todo.

[...] a gente não fala que Deus está no Céu, Deus está em Nós, porque se Deus está no Céu ele está muito longe, você fica chamando ele, mas se você tem a consciência que ele vive em nós só é preciso dominar, aprender a dominar, o que já é seu, ele assoprou nas suas narinas, ele fez imagem e semelhança, então o mesmo poder que Deus tem, nós temos em parte, pra explicar melhor, Deus é um oceano, e nós somos uma gota, a gota do oceano tem os mesmos elementos que todo o oceano, então essa é a consciência que o homem Rasta procura redesenvolver [...] (BS1).

Para o pensamento Rastafári o todo (Jah) está presente nas partes, assim como as partes possuem a essência do todo, aproximando-se da noção Moriniana $^{18}$ de circuito relacional; ideia que afirma ser impossível conhecer as partes sem conhecer o todo.

A Cultura Rastafári é também baseada no autoconhecimento, intuição e sabedoria natural do ser humano, o subjetivo é valorizado e respeitado, porém a imposição de valores, de crenças e a dominação física e/ou psicológica são fortemente rejeitadas. Os depoimentos mostram que o Rastafári é um ser livre que através do autoconhecimento e da autogestão estrutura sua autonomia.

[...] Particularmente vejo o ser "Rastafári" como um homem livre, que faz suas opções de vida de acordo com a sua consciência e não de acordo com a maneira como a sociedade tenta moldar (SLD2).

[...] uma autogestão com essa grande parceira que é a natureza $[\ldots]$ (BS1)

Essas informações relacionam-se com a afirmação de Bertolucci ${ }^{19}$ que estuda a perspectiva transpessoal em psicoterapia, onde relata que a alienação é o afastamento da consciência que torna o indivíduo manipulável, não havendo possibilidade de manipulação quando a consciência está desenvolvida.
A Cultura Rastafári valoriza a observação do mundo através de uma ótica ampla, interconectada e interdependente, considera que na verdade tudo é parte integrante de um grande sistema, ao contrário da medicina Biomédica que possui visão mecanicista e separatista, como podemos ver no relato abaixo:

[...] a cultura negra é uma cultura de unidade e não de divisão, diferente da cultura branca, os brancos pegaram a medicina e dividiram em várias partes [...] Então na África, em Abissínia, porque esse nome África também é uma referência a esse continente dividido, mas o nome Abissínia é referência ao continente que não era dividido, e nada era dividido, a medicina não era dividida, a medicina do homem africano é dividida somente em corpo, mente e espirito,[...] A maneira de pensar africana é essa, não pode dividir uma coisa que é única, isso é um desenvolvimento externo de África, que foi feitos nas civilizações, esta divisão é para estabelecer o controle [...] (BS1).

Narrativa esta que lembra o pensamento de Edgar Morin $^{18-20}$, porque critica a concepção reducionista de conhecimento e propõe uma concepção multidimensional, pois acredita que a inteligência parcelada, mecanicista e compartimentada, fragmenta os problemas, separa o que está unido fazendo com que muitas vezes não seja possível identificar o que realmente importa. Tais críticas também possuem relação direta com o discurso de Siqueira et $\mathrm{a}^{21}$ que afirma encontrar limitações na abordagem preconizada no modelo convencional de saúde, pois o modelo convencional limita-se à cura de doenças ou tratamento de sintomas e não contribui para o processo de saúde-doença e qualidade de vida do cliente.

Podemos observar que as características cosmológicas da Cultura Rastafári possuem grande semelhança ao discurso do paradigma Vitalista descrito por Nascimento ${ }^{15}$ que entende a saúde como conectada ao meio ambiente, centrado na saúde e na busca de harmonia da pessoa com seu meio ambiente natural e social, valorizando a subjetividade individual, a prevenção e a promoção da saúde e a integralidade do cuidado.

\subsection{DOUTRINA MÉDICA}

Doutrina médica é a dimensão das Racionalidades Médicas que através de formulação de certas concepções teóricas, define o que é o processo saúde-doença, o que é a doença ou adoecimento, em suas origens ou 
causas, o que é passível de tratar ou curar (na biomedicina, o que pertence ou não à clínica) e as causas e a natureza do adoecer no homem ${ }^{15-14}$. A concepção de saúde para o pensamento Rastafári é estruturada totalmente em sua cosmologia naturalista de integração e autoconhecimento, desta forma toda a saúde, depende da conexão com o Eu divino que vive em todos os seres e com a integração e entendimento do funcionamento da natureza. As doenças são a manifestação do distanciamento da natureza interior (pessoal) e exterior (meio). Quando um indivíduo adoece é porque o mesmo estaria deixando de ouvir sua sabedoria interior, ideia que pressupõe um afastamento da harmonia natural presente no meio ambiente original.

Quando falamos de saúde não podemos nos restringir ao corpo físico, não existe saúde unilateral, a saúde tem que ser integral, o corpo, a mente, a alma tem que estar em equilíbrio para haver garantia de saúde integral. Para o corpo é importante bons alimentos, para a mente é importante bons pensamentos, para a alma é importante bons sentimentos. É importante saber escutar o corpo, conversar com o corpo, sentir suas necessidades, assim como é importante escutar o coração para mantê-lo sempre feliz [...] (SLD2).

O pensamento Rastafári pode ser filiado ao conceito de saúde integral porque reconhece a importância do cuidado adequado em todos os níveis, tanto fisicamente, mentalmente e espiritualmente. Nas sociedades baseadas no paradigma naturalista os indivíduos são concebidos como elementos integrantes de uma grande teia natural, a teia da vida ${ }^{14}$.

Segundo Boff ${ }^{22}$ cuidar da saúde significa manter a visão integral, buscando um equilíbrio sempre por construir entre o corpo, a mente e o espírito. Para manter a saúde se faz necessário reconhecer todas as dimensões as quais o ser pertence.

Pelos relatos obtidos na pesquisa de campo, a alimentação natural, orgânica, integral, sem industrialização ou conservantes é um grande pilar da saúde Rastafári.

Por Rastafári trazer uma consciência voltada para o vegetarianismo, existe uma reeducação alimentar, em questão de comer o que vem da terra, alimentar-se de coisas orgânicas e não industrializadas, alimento vivo e rico em vitaminas e proteínas, temos menos índices de problemas em relação á saúde, por usarmos o alimento como medicina natural (BS3).
O pensamento Rastafári possui uma concepção ampla no quesito alimentação, pois transcendem a visão comum de que alimentação é comida, que se ingere apenas através da cavidade bucal, para o Rastafári alimentação não é só o que se come, e sim tudo o que se absorve do ambiente através dos sentidos, por exemplo, tanto um prato de comida pode ser considerado alimentação quanto uma música, algo que pode ser captado através da visão, da meditação, ou até mesmo uma conversa construtiva, podem ser concebidas como alimentação por esta perspectiva.

[...] começa pela mente a saúde do Rasta, deixar de fazer certas coisas que não produzem saúde, deixar de ouvir certas coisas, deixar de ver certas coisas, deixar de respirar certas coisas, que não é somente o que você come que te traz saúde, mas o que você vê, o que você ouve, e o ar que você respira, a saúde do Rasta está ligada aos sete selos, que são os sete buracos que nós temos na nossa face, tudo é importante para contribuir com a saúde do Rasta (BS1).

Existe também a consciência da importância do exercício físico.

[...] outra contribuição para a saúde é valorizar o movimento, como água devemos sempre estar em movimento, homem parado é igual água parada $\mathrm{e}$ estraga [...] (BS4).

Com o exercício físico, pode-se obter melhor funcionamento orgânico geral, mais disposição física e mental, aumento do bem estar em geral, mais bom-humor, maior equilibro mental e emocional ${ }^{23}$.

Para o pensamento Rastafári a doença é também, fruto da miscigenação de ideias, da perda das raízes ideológicas e da distorção da sua cultura original.

[...] a gente vê hoje homens negros dizendo que são brancos, a gente vê o negro sempre submisso [...] quando você está pensando com a mente de outro povo sua mente foi arrancada, você é índio e está pensando como europeu, então naturalmente você vai ficar doente, mas não da doença do índio, mas da doença do europeu, então vai ter que buscar o europeu pra te curar e então o índio deixa de acreditar no pajé, deixa de acreditar no cachimbo da paz que cura ele, porque é a doença do europeu e só o europeu vai ter a cura, botando todo o poder na mão do europeu e tirando o poder interno que todos nós temos [...] então uma vez retornemos, é fato que teremos uma saúde mental, mais coerente, e posteriormente o corpo vai ser saudável também [...] (BS1). 
Segundo autores como Rabelo e Chevannes ${ }^{4-2}$ é possível identificar na concepção Rastafári de doença um laço estreito com o processo de escravidão moderna sofrido pelos povos africanos. Segundo Rabelo ${ }^{4}$ desde o início do movimento Rastafári até hoje, existe um grande esforço para curar as feridas causadas pela escravidão dos povos nativos, principalmente o povo negro. Para Chevannes ${ }^{2}$ a escravidão age principalmente em dois níveis: o primeiro é na força bruta, física, na corrente, no chicote, sem ela seria impossível manter a escravidão do povo. $E$ a segunda ainda mais poderosa, é que todos os sistemas de escravidão tentavam apoiar a escravidão a partir da ideologia de que os negros seriam selvagens não civilizados, considerados inferiores. Estas feridas, atualmente se apresentam em predominância na forma de subjugação e desequilíbrio psicológico, criados a partir da destruição das heranças africanas e da humilhação sofrida pelos povos nativos.

\subsection{SISTEMA TERAPÊUTICO.}

Sistema terapêutico compreende a pluralidade de técnicas pelas quais se determinam as formas de atuação médicas e terapêuticas, as intervenções adequadas para o tratamento de cada processo mórbido (ou doença) identificado pela diagnose ${ }^{15}$. A Cosmologia da Cultura Rastafári é a grande norteadora de toda a ação dos adeptos, desta forma, tudo que é produzido ou executado pelo praticante sempre é feito a partir da ótica das múltiplas dimensões (corpo, mente e espírito) do ser humano, de forma a abordar de maneira integral estas dimensões, ao elaborar um tratamento.

[...] não é só produzir o remédio das plantas, mas até o que está pensando na hora que está produzindo este remédio, a gente faz uma reverência antes pra se sintonizar entrar na meditação, então começamos a preparar o medicamento, acendemos o fogo, buscamos a água, a gente abençoa para que a energia flua, se fizer aquilo de qualquer jeito vai dar um resultado, mas não vai ser o mesmo que se fizer na meditação em três dimensões, fisicamente, mentalmente e espiritualmente, ou seja, para fazer um remédio, fisicamente o seu corpo deve estar limpo, suas mãos devem estar limpas, a cozinha os utensilios, espiritualmente tem que estar limpo, não vai ficar falando palavras ruins neste momento, $e$ mentalmente tem que estar limpo também, imagina se você faz um remédio pensando só em problema, você está colocando essa energia também [...] (BS1).
A utilização das plantas medicinais é parte de um conhecimento gerado a partir de muitas gerações. Possuem grande importância para o cuidado e manutenção da saúde do Rastafári. Além da ação terapêutica, a fitoterapia constitui parte importante das culturas e das identidades africanas que, no contexto Rastafári, são representadas pelos Bush Doctors ${ }^{8}$.

Existem muitas formas de utilizar as plantas, mas é elaborado principalmente a partir da necessidade, pois nós usamos, por exemplo, a babosa internamente e externamente, dependendo da necessidade, usamos a babosa em infusão, usamos na alimentação, em uso tópico, no cabelo, tomamos chás, fumamos alguns tipos de ervas [...] tem várias formas, dependendo da necessidade e do poder que quer tirar da planta, é basicamente a mesma cultura que nós vemos na Ayurveda e na medicina chinesa natural, tudo isso teve origem na etiópia, em Kush, para nós etiópia é toda a Âfrica, mas principalmente aquela região que a gente conhece como chifre da África, Egito, Sudão e parte da Arábia, todo esse desenvolvimento começou ali [...] (BS1).

Outra ferramenta da terapêutica Rastafári é a música. A partir dela é possível alcançar estados elevados de consciência, é um dos elementos que possibilitam a religação, a conexão com a essência da vida, com a natureza ancestral, com Deus. Constitui importante componente dos rituais, das celebrações que através dela e dos louvores os integrantes alcançam o êxtase coletivo. A música Rastafári também é muitas vezes uma forma de traduzir os lamentos e insatisfações com as injustiças sociais ${ }^{24}$.
A função da música pra o Rasta é sempre se manter num estado de meditação, na vibração positiva. A música cura a frustração, depressão e outros obstá- culos mentais que uma pessoa passa enquanto está em contato com o mundo material [...] (SLD1).

A meditação também é uma técnica terapêutica muito presente na Cultura Rastafári. Esta técnica consiste basicamente em focar a atenção e ampliar a consciência. É uma auto-observação, uma abertura mental para o divino, invocando a orientação de um poder mais alto, também considerada como a análise racional de ensinamentos religiosos.

[...] a meditação para o homem rastafári é estar sempre consciente de todos os movimentos [...] é um estado mental que o homem Rastafári procura ter a todo o momento, não só quando ele está meditando em certa posição ou trabalhando em certo ritual, mas a meditação do homem Rastafári é estar sempre com a sua consciência e sua mente capaz de 
entender o que está se passando com você a todo momento e em qualquer ambiente [...] (BS1).

A meditação é capaz de estimular aspectos saudáveis e está muito associada à saúde mental ${ }^{10}$.Um dos entrevistados trouxe a consciência do benefício terapêutico do banho frio, que afirma aumentar a imunidade.

[...] Alguns sacerdotes ensinam a medicina dos banhos gelados, que reforçam o seu sistema imunológico mesmo que more numa região fria é saudável tomar uma banho com a água na temperatura normal [...] (BS1).

Segundo Andrade et $\mathrm{al}^{25}$, a Talassoterapia (terapia baseada nos banhos de mar) e balneoterapia (banhos terapêuticos), são modalidades terapêuticas utilizadas há vários anos em muitas regiões do mundo na prevenção e no tratamento de diversas enfermidades.

O Jejum também foi uma prática de cura e manutenção da saúde encontrada na Cultura Rastafári, podemos observar no relato abaixo que os adeptos da Cultura Rastafári utilizam do jejum para realizar purificação corporal, ampliação da consciência e edificação mental.

[...] jejum é uma das técnicas de saúde e purificação que os Rastas praticam, geralmente praticamos três vezes por semana um jejum de doze horas que vai da meia noite até o meio dia, na segunda, na quarta e no sábado que é o dia sagrado.[...] na quaresma jejuamos todos os quarenta dias para purificar o corpo e também para nos trazer uma consciência mental de que muitas pessoas passam fome no mundo e que nós temos que reconhecer isto, não só vendo, mas sentindo o que é a fome, e dominar a fome, o jejum também tem esse lado mental, a edificação [...] (BS1).

Segundo o Manual de Assistência Espiritual e Religiosa Hospitalar ${ }^{26}$ para a fé Bahaí o jejum simboliza o desprendimento do físico, é de natureza essencialmente espiritual e constitui um período de meditação e renovação interior. Ainda de acordo com o Manual, adeptos de outras religiões como Católicos, Muçulmanos, Judeus e Praticantes da igreja Ortodoxa também utilizam dos jejuns em suas práticas religiosas.

\section{NATUROLOGIA E MEDICINA RASTAFARI: CONSIDERAÇÕES FINAIS.}

Esta pesquisa possibilitou encontrar informações importantes sobre a Cultura Rastafári e seu sistema médico. Pode-se observar que pelo fato da pesquisa de campo ter sido realizada com sacerdotes, profetas e praticantes do Rastafári, e pela ausência de médicos Rastafáris ou Bush Doctors, os relatos obtidos trouxeram mais elucidações no quesito de cosmologia do que em doutrina médica e sistemas terapêuticos.

Diante dos resultados foi possível elucidar que assim como a Naturologia, a cosmologia da Cultura Rastafári e consequentemente de sua medicina, possuem caráter multidimensional e complexo, traços característicos do paradigma vitalista em saúde e propõe que o olhar terapêutico seja integrativo: leva em consideração o ser humano em seus aspectos físicos, emocionais, mentais, espirituais, ambientais e sociais.

Pode-se observar que as características acima fazem parte do paradigma Naturológico, pois, segundo Portella ${ }^{27}$ a Naturologia pode ser definida como:

Um conhecimento da área da saúde embasado na pluralidade de sistemas terapêuticos complexos vitalistas que parte de uma visão multidimensional do processo saúde-doença, da relação de interagência e de práticas integrativas e complementares no cuidado e atenção à saúde.

Por apresentar concepções semelhantes ao paradigma Naturológico é possível pensar que a Medicina Rastafári constitui uma linha terapêutica compatível às práticas Naturológicas, podendo futuramente ser incorporada ao leque de Racionalidades Médicas abordadas pela Naturologia e a área da saúde em geral, pois, trata-se de um conjunto integrado e estruturado de práticas e saberes.

\section{CONFLITOS DE INTERESSE}

Não declarado.

\section{FONTES DE FINANCIAMENTO}

Não declarado. 


\section{BIBLIOGRAFIA}

1. Silva A E. Repensar a História: Um diálogo entre saberes. São Paulo, 2012

2. Chevannes B. Rastafari: Roots and ideology. Syracuse University Press 1994.

3. Cardoso M A. A magia do Reggae. São Paulo: Martin Clarete 1997.

4. Rabelo D. Rastafari. Identidade e hibridismo cultural na Jamaica, 1930-1981. Brasília, 2006

5. Turner T E, Ferguson B J. Arise ye mighty people: Gender, class \& race in popular struggles. Trenton: Africa World, 1994.

6. Cunha O M. Fazendo a "coisa certa": reggae, Rastas e pentecostais em Salvador. Revista brasileira de ciências sociais 1993. [acessado 2014 Nov 2] Disponível em: http://www.anpocs.org.br/portal/ publicacoes/rbcs23_09.htm.

7. Bogues J L. Rastafarian foods habits 1976. [acessado 2014 Apr 2014] Disponível em http://agris.fao.org/agris-search/search. do? recordid=us201302986917.

8. Philander L. An emergente ethnomedicine: rastafari bush doctors in the Western Cape. South Africa, 2010.

9. Kailash K L. Holistic healing from the caribbean: na interview with Hon. Priest Kailash Kay Leone: Depoimento: 2012 Feb 8: Global cariben media. Entrevista concedida a Terri Henry. [Acessado em: 2014 Oct 29] Disponível em: http://www.mnialive.com/articles/ holistc-healing-from-the-caribbean-an-interview-with-hon-priestkailash-kay-leone.

10. Menezes C B, Dellaglio D D. Por que Meditar? A experiência subjetiva da prática de meditação. Psicologia em estudo, v. 14 n.3, p. 565-573, 2010.

11. Chizzotti, A. Pesquisa em ciências humanas e sociais. $7^{\text {a }}$ Ed. São Paulo: Cortez, 2005

12. Atkinson R, Flint J. Acessing hidden and hard-to-reach populations: Snowball research strategies. Social research update, v. 33 nl, p.1-4, 2001.

13. Luz M T. Racionalidades Médicas e Terapêuticas Alternativas. Cadernos de sociologia, v.7, p. 109-128, 1995.

14. Tesser C D, Luz M T. Racionalidades Médicas e Integralidade. Ciência Saúde Coletiva, v. 13 n.1, 2008.

15. Nascimento M C, Barros N F, Nogueira M I, Luz M T. A categoria racionalidade médica e uma nova epistemologia em saúde. Ciência Saúde Coletiva, 2013.

16. Gomes D V. Educação para o consumo ético e sustentável. Revista eletrônica do mestrado em educação ambiental, v. 16, p.18-31, 2006.

17. Capra F, Eichemberg N R. A teia da vida: uma nova compreenção científica dos sistemas vivos. Editora Cultrix 2006.

18. Morin E. Os sete saberes necessários à educação do futuro. Brasília: Cortez, 2000.

19. Bertolucci E. Psicologia do sagrado: psicoterapia transpessoal. São Paulo: Agora, 1991.
20. Morin E. A necessidade de um pensamento complexo. Reapresentação e complexidade. Rio de Janeiro: Garamond, 2003.

21. Siqueira K M, Barbosa M A, Brasil V V, Oliveira L M C, Andraus L M S. Crenças populares referentes à saúde: apropriação de saberes sócio-culturais. Texto \& Contexto-Enfermagem, v.15, n.1, p. 68-73, 2006. [acessado 2014 Nov 2] Disponível em: http://www.scielo.br/ scielo.php?pid_saberes_socio-culturais_texto_\&_contexto

22. Boff L. Saber cuidar: ética do humano. Petrópolis: Vozes, 1999.

23. Samulski M D, Noce A F. A importância da atividade física para a saúde e qualidade de vida: um estudo entre professores, alunos e funcionários da UFMG. Revista Brasileira de Atividade Física \& Saúde, v. 5 n.1, p.5-21 2012

24. Yawney C. Rasta mek a trod: symbolic ambiguity in a globalizing religion. Arise ye mighty peoople, 1994.

25. Andrade S C, Carvalho R F P P, Soares A S, Vilar M J. Benefits of thalassotherapy and balneotherapy for fibromyalgia. Revista brasileira de reumatologia, 2008. [acessado 2014 Nov 10] Disponível em: http://scielo.br/scielo.php?pid=S048250042008000200005\&script=sci_arttext

26. Manual de Assistencia Espiritual e Religiosa Hospitalar. Pastoral da Saúde 2009. [Acessado 2014 Nov. 11] Disponível em: http://www. agencia.ecclesia.pt/dlds/bo/Manual_Assist_Espiritual.pdf.

27. Portella C F. Naturologia, transdiciplinaridade e transracionalidade. Cardenos de Naturologia e terapias complementares, v. 2 n.3, p.57-65 2014

28. Rabelo D. Obeah e Myalism: Religiosidade, feitiçaria e magia afro-jamaicanas. Revista Brasileira do Caribe. (2007).

29. Nel R. Igrejas Independentes Africanas redefinindo interculturação? Uma avaliação teológica negro-africana. Protestantinismo em Revista, v.28, p. 35-40, 2012

30. Lima I M. Todos os negros são africanos? O Pan-Africanismo e suas ressonâncias no Brasil comtemporâneo. Anais do XXVI Simpósio Nacional de História - ANPUH. São Paulo, 2011.

v Complexo de Crenças provenientes da zona rural jamaicana que envolvem feitiçaria e magia por meio de encantamentos e a utilização de espíritos ou fantasmas que podem ajudar ou prejudicar as pessoas. Embora sejam condenados por grande parte da sociedade envolvente, eles persistem como forma de resistência e estratégias de sobrevivência das populações afro-jamaicanas marginalizadas $\left(\right.$ Rabelo $\left.^{28}\right)$.

1 Movimento religioso com a visão africana de cristianismo e a criação de igrejas cristãs na África $\left(\mathrm{Nel}^{29}\right)$.

1 Ideologia que propõem a união de todos os povos de África como forma de potencializar a voz do continente no contexto internacional, em parte responsável pelo surgimento da Organização de Unidade Africana, tem sido mais defendido fora de África, entre os descendentes dos escravos africanos $\left(\mathrm{Lima}^{30}\right)$.

1 Ritual espiritual que se insere no contexto Rastafári e tem como fundamentação a propagação da cultura, salvação e elevação espiritual através da música ancestral (Yawney ${ }^{24}$ ). 